\title{
CATALYTIC ACTIVITY OF ZSM-5 ZEOLITE LOADED WITH TRANSITION METALS FOR THE SELECTIVE CATALYTIC REDUCTION OF NOx
}

\author{
I.M. Saaid, A.R. Mohamed and S. Bhatia* \\ School of Chemical Engineering, Universiti Sains Malaysia, Engineering Campus, \\ 14300 Nibong Tebal, P. Pinang, Malaysia.
}

Received 30 April 2002, Accepted 4 July 2002

\begin{abstract}
Catalytic activity measurement were carried out on catalysts formulated from ZSM-5 zeolite separately loaded with transition metals $(\mathrm{Cu}, \mathrm{Co}, \mathrm{Ni}, \mathrm{Fe})$ for the removal of NOx in simulated diesel exhaust conditions. Various factors were investigated to compare the performance of these catalysts including catalyst preparation method, Si/Al ratio of the parent zeolite support, and durability in the exhaust stream containing water vapor or $\mathrm{SO}_{2}$. In many experimental conditions except in the presence of water vapor or $\mathrm{SO}_{2}$, $\mathrm{Cu}$-ZSM5 remained the most active catalyst with $100 \%$ NOx conversion at around $350^{\circ}$ C. Co-ZSM5 and Ni-ZSM5 could also achieve complete NOx conversion but at a much higher temperature of around $450^{\circ} \mathrm{C}$. Fe-ZSM5 catalyst was the least active catalyst probably due to the formation of iron oxide particle, which accelerated formation of carbon monoxide.
\end{abstract}

Keywords: Selective catalytic reduction, Cu-ZSM5, Co-ZSM5, Fe-ZSM5, Ni-ZSM5

\section{INTRODUCTION}

Increasingly stringent limits for exhaust emissions, particularly for nitrogen oxides (NOx) from lean burn engine such as diesel have driven many researchers to look for suitable reduction techniques [1,2]. It appears that diesel vehicles, known for its economical fuel consumption, high thermal efficiency and low $\mathrm{CO}$ emission, might be eventually phased out in the near future if the current level of NOx emission is not reduced. Selective catalytic reduction with hydrocarbon as a reducing agent, HC-SCR, has been widely reported as a promising technique for NOx reduction in excess of oxygen $[2,3,4,5]$.

$$
2 \mathrm{NOx}+\mathrm{HC}+a \mathrm{O}_{2} \rightarrow \mathrm{N}_{2}+b \mathrm{CO}_{2}+c \mathrm{H}_{2} \mathrm{O}
$$

*Corresponding author - e-mail: chbhatia@eng.usm.my, Fax: +60-4-594-1013, Tel: +60-4-593-7788 
The HC-SCR technique eliminates $\mathrm{NH}_{3}$ and its associated control and storage system, typically used in the traditional SCR method in power or nitric acid plants. Further development of the HC-SCR technique is often centered on finding the suitable catalyst. This is because many of the proposed catalysts tend to easily deactivate in water vapor or $\mathrm{SO}_{2}[3,6]$, provide narrow temperature window for optimum performance $[4,7]$ and show high tendency to promote formation of undesired by-products especially carbon monoxide (CO) [7] and nitrous oxide $\left(\mathrm{N}_{2} \mathrm{O}\right)$ [4]. Many studies reported that transition metals such as copper, cobalt, iron and nickel supported on H-ZSM-5 showed promising results for the removal of NOx through HC-SCR process $[8,9,10]$. While the type of metal and support material primarily determine the suitability of the catalyst for the removal of NOx, other minor factors could also influence the activity of the supported catalyst. These factors included characteristics of supports, types of hydrocarbons and methods of catalyst preparation. The last factor plays a critical role to ensure that only a certain active species of a metal is incorporated in the support structure. This is because some metal species especially in their oxide forms tend to act as another catalyst to produce undesired by-products.

Comparison and evaluation of reported results are not practical due to the wide variation of experimental conditions. Therefore it is our intention to experimentally compare catalytic activities of several transition metals (i.e. $\mathrm{Cu}, \mathrm{Co}, \mathrm{Ni}$ and $\mathrm{Fe}$ ) loaded on ZSM5 zeolite for the reduction of NOx in the HC-SCR system. Catalytic activities were measured in synthetic diesel exhaust conditions that include a range of temperature, presence of water vapor and $\mathrm{SO}_{2}$, changes to the $\mathrm{Si} / \mathrm{Al}$ of the zeolite support, and catalyst preparation method. Experimental results, which form a basis for our further catalyst development, are discussed with reference to reported studies.

\section{EXPERIMENTAL}

\subsection{Catalyst preparation}

H-ZSM-5 zeolite supports were received from Süd Chemie AG, with Si/Al ratios of 45, 90, 240, and 400 respectively. These were analyzed with nitrogen adsorption isotherm technique (Autosorb IC, Quantachrome, U.S.A) to determine the BET surface area, pore volume and pore size distribution as presented Table 1. Prior to metal loading, the four samples of H-ZSM5 zeolites were dried overnight in oven at $100^{\circ} \mathrm{C}$ to remove trapped water vapor. Then the temperature was increased step-wise at $5^{\circ} \mathrm{C}$. $\mathrm{min}^{-1}$ and held for 1 hour at $500{ }^{\circ} \mathrm{C}$. Chemical sources for metals were copper(II) nitrate tri-hydrate $\left(\mathrm{Cu}\left(\mathrm{NO}_{3}\right)_{2} \cdot 3 \mathrm{H}_{2} \mathrm{O}\right)$, Merck, $\left.99.5 \%\right)$, copper(III) acetate monohydrate $\left(\mathrm{Cu}\left(\mathrm{CH}_{3} \mathrm{COO}\right)_{2} \cdot \mathrm{H}_{2} \mathrm{O}\right)$, Merck, 99\%), cobalt nitrate hexa-hydrate $\left(\mathrm{Co}\left(\mathrm{NO}_{3}\right)_{2} \cdot 6 \mathrm{H}_{2} \mathrm{O}\right)$, Fluka, 98\%), nickel nitrate hexa-hydrate $\left(\mathrm{Ni}\left(\mathrm{NO}_{3}\right)_{2} \cdot 6 \mathrm{H}_{2} \mathrm{O}\right)$, Merck, 99\%), iron(III) chloride $\left(\mathrm{FeCl}_{3}, \mathrm{Merck}, 98 \%\right)$ and iron(II) sulfate hepta-hydrate $\left(\left(\mathrm{FeSO}_{4} .7 \mathrm{H}_{2} \mathrm{O}\right)\right.$, Merck, $99.5 \%)$. 
Table 1 : Surface properties of samples of H-ZSM5 zeolites as analyzed by Autosorb IC* (Quantachrome).

\begin{tabular}{|l|c|c|c|c|c|}
\hline Parent Zeolite & Si/A & $\begin{array}{c}\text { Meso Pore } \\
\text { Area } \\
\left(\mathbf{m}^{2} \mathbf{g}^{-1}\right)\end{array}$ & $\begin{array}{c}\text { Micro Pore } \\
\text { Area } \\
\left(\mathbf{m}^{\mathbf{2}} \mathbf{g}^{-1}\right)\end{array}$ & $\begin{array}{c}\text { Micro Pore } \\
\text { Volume }(\mathbf{t}) \\
\left(\mathbf{c c .} \mathbf{g}^{-1}\right)\end{array}$ & $\begin{array}{c}\text { BET Surface } \\
\text { Area } \\
\left(\mathbf{m}^{2} \mathbf{g}^{-1}\right)\end{array}$ \\
\hline H-ZSM5 (45) & 45 & 162 & 207 & 0.118 & 369 \\
H-ZSM5 (90) & 90 & 188 & 187 & 0.142 & 375 \\
H-ZSM5 (240) & 240 & 220 & 111 & 0.145 & 331 \\
H-ZSM5 (400) & 400 & 324 & 33 & 0.016 & 357 \\
\hline
\end{tabular}

*Analysis is based on 5-point nitrogen adsorption isotherm.

Table 2: Main characteristics of the studied samples

\begin{tabular}{|c|c|c|c|c|}
\hline Catalyst & Si/Al & Preparation & $\begin{array}{c}\text { BET Area } \\
\mathbf{m}^{\mathbf{2}} \mathbf{g}\end{array}$ & $\begin{array}{c}\text { Metal Content } \\
\mathbf{w t .} \%\end{array}$ \\
\hline \multirow{4}{*}{ Cu-ZSM5 } & 45 & WIE & 367 & 3.78 \\
\cline { 2 - 5 } & 45 & IMP & 383 & 6.27 \\
\cline { 2 - 5 } & 90 & WIE & 372 & 5.27 \\
\cline { 2 - 5 } & 240 & WIE & 377 & 6.05 \\
\hline \multirow{2}{*}{ Co-ZSM5 } & 400 & WIE & 391 & 7.01 \\
\hline \multirow{3}{*}{ Fe-ZSM5 } & $45 *$ & WIE & 359 & 1.65 \\
\cline { 2 - 5 } & 45 & WIE & 364 & 2.74 \\
\cline { 2 - 5 } & 45 & IMP & 379 & 5.07 \\
\hline \multirow{2}{*}{ Ni-ZSM5 } & 45 & SSI & 380 & 4.67 \\
\hline
\end{tabular}

a Determined by nitrogen adsorption isotherm (Autosorb 1C, Quantachrome)

${ }^{b}$ Determined by Atomic Adsorption Spectroscopy

Essentially, metals were loaded into the zeolite support through excessive wet ion exchange (WIE) and impregnation (IMP) methods. In the WIE method, 10 gram of calcined H-ZSM-5 zeolite was immersed and continuously stirred in $100 \mathrm{ml} 0.01 \mathrm{M}$ of respective metal nitrate or acetate solution for a period of at least 8 hours. The $\mathrm{pH}$ and temperature of the slurry were kept at about 7 and $40^{\circ} \mathrm{C}$ respectively to avoid possible formation of metal hydroxides or metal oxides. At the end of the 8-hour period, the 
slurry was vacuum filtered and re-exchanged in a fresh nitrate solution for continuous stirring. These steps were repeated three times before the slurry was finally vacuum filtered and washed three times with de-ionized water to remove excess nitrates, acetate or sulfates (i.e. for copper acetate or iron sulfate solutions). The powder catalyst was dried overnight at $100^{\circ} \mathrm{C}$ in the oven. The temperature was gradually increased at $2^{\circ}$ $\mathrm{C} / \mathrm{min}$ until it reached $500^{\circ} \mathrm{C}$ where it was kept 1 hour for calcination.

In the IMP method, 10 gram of H-ZSM5 zeolite powder was put into $10 \mathrm{ml}$. of nitrate solution containing $3 \%$ concentration of respective metal ions. The slurry was then placed in the rotavapor unit equipped with water-bath and vacuum system (Büchi Model R 114, B 480, and B 169). The unit continuously rotated in the water-bath set at $80^{\circ} \mathrm{C}$ until the slurry became completely dried and free flowing. The powder catalyst was then removed and dried overnight at $100^{\circ} \mathrm{C}$ before calcination at $500^{\circ} \mathrm{C}$.

For the preparation of Fe-ZSM5 catalysts, two additional methods were used with detailed procedures reported in the literature: solid-state ion exchange (SSI) [11,12] and sublimation (SUB) [7]. In the SSI method, $10 \mathrm{~g}$. of zeolite sample and 2 gram of $\mathrm{FeCl}_{3}$ were uniformly ground in an agate mortar. The mixture was then heated for 12 hours at $400^{\circ} \mathrm{C}$ in flowing $\mathrm{N}_{2}$. After cooling, it was doubly washed with de-ionized water and dried overnight at $100^{\circ} \mathrm{C}$ before calcination.

The SUB process was carried out using a special set up consisting of a U-shape quartz reactor as proposed in the literature [7]. Before sublimation process, the ZSM-5 zeolite bed was pre-conditioned overnight in $\mathrm{N}_{2}$ flow at $100^{\circ} \mathrm{C}$ to remove traces of oxygen. Then the temperature of the zeolite bed was raised and kept at $320^{\circ} \mathrm{C}$ in $\mathrm{N}_{2}$ flow of 100 $\mathrm{ml} / \mathrm{min}$. When the zeolite bed had become uniformly yellow after about 1 hour, the sublimation process was stopped and the sample was removed and washed doubly with de-ionized water before drying overnight in oven.

\subsection{Catalytic activity measurement}

Dried catalyst samples were pressed under 3-5 tons (Graseby Specac hydraulic pump) pressure load and meshed into $250-350 \mu \mathrm{m}$ particles before testing in the experimental set up in Figure 1. The stainless steel micro-catalytic reactor $(9.5 \mathrm{~mm}$ O.D. and $6.0 \mathrm{~mm}$ I.D.) was placed horizontally in a mini tubular furnace (Lindberg Blue M) equipped with digital temperature controller. In all experimental runs, $0.18 \mathrm{~g}$. of catalyst with an apparent density of $0.52 \mathrm{~g} . \mathrm{cm}^{-3}$ was used in gas flow rate of $100 \mathrm{ml} / \mathrm{min}$ corresponding to about $18,000 \mathrm{hr}^{-1}$ gas hourly space velocity. The catalyst bed was supported at both ends by quartz wool plugs. Type $\mathrm{K}$ thermocouple inside the reactor and connected to digital scanning thermometer (Cole Palmer model 92000-05) was used to measure the catalyst bed temperature. The catalyst was activated in situ by heating at $500^{\circ} \mathrm{C}$ for 1 hour in flowing $\mathrm{O}_{2}(100 \mathrm{ml} / \mathrm{min})$ to remove possible organic impurities before feeding with the synthetic exhaust gas consisting of $1000 \mathrm{ppm} \mathrm{NO}, 1500 \mathrm{ppm} \mathrm{i-} \mathrm{C}_{4} \mathrm{H}_{10}$ and $3 \%$ 


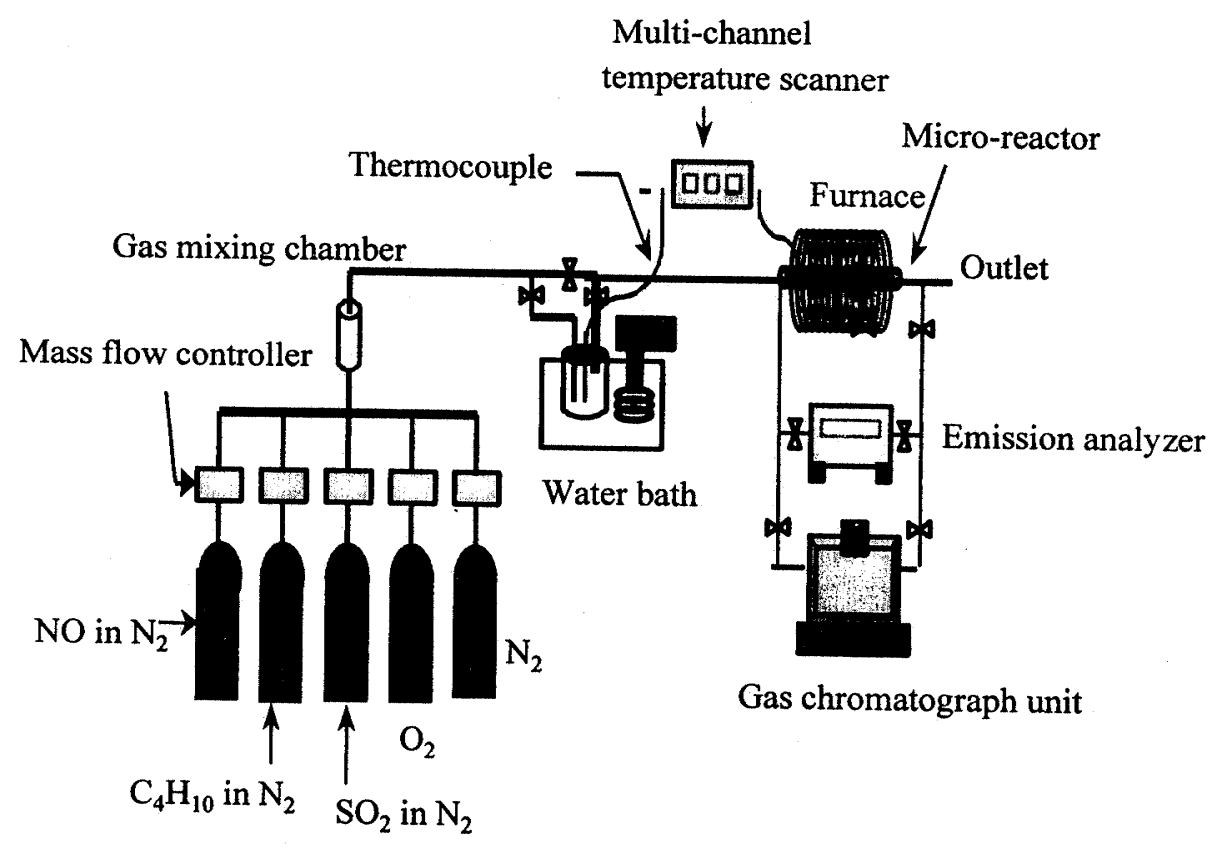

Figure 1: Experimental set-up for catalytic activity measürement

$\mathrm{O}_{2}$ in $\mathrm{N}_{2}$ balance. Mass flow controllers (MKS type 1179A) connected to a 4-channel control box (MKS type 247) were used to control individual gas flow rate and concentration. Gas composition at the inlet and outlet of the reactor was analyzed by online gas chromatograph (Shimadzu 8A) equipped with Porapak Q column (80/100 mesh size) for the separation of $\mathrm{i}-\mathrm{C}_{4} \mathrm{H}_{10}, \mathrm{CO}_{2}, \mathrm{~N}_{2} \mathrm{O}$ and $\mathrm{N}_{2}$ or $\mathrm{O}_{2}$ and Molecular Sieve $5 \mathrm{~A}$ for the separation of $\mathrm{N}_{2}, \mathrm{O}_{2}$ and $\mathrm{CO}$. Beside the online gas chromatograph, ENERAC $2000 \mathrm{E}$ emission analyzer was also used to measure concentrations of $\mathrm{NO}, \mathrm{NO}_{2}, \mathrm{CO}$ and $\mathrm{SO}_{2}$. The catalyst was exposed to a desired set of conditions for about an hour before taking any measurement. The percentage reduction of NOx $(\mathrm{X})$ was calculated based on the difference between the total measured concentration of $\mathrm{NO}$ and $\mathrm{NO}_{2}$ at the inlet $\left(\mathrm{C}_{\mathrm{in}}\right)$ and outlet $\left(\mathrm{C}_{\mathrm{out}}\right)$ as expressed by equation (2).

Reduction of NOx, $\mathrm{X}=\frac{\mathrm{C}_{\mathrm{in}}-\mathrm{C}_{\text {out }}}{\mathrm{C}_{\mathrm{in}}} \times 100 \%$

\section{EXPERIMENTAL RESULTS}

\subsection{Temperature profiles}

Results from catalytic activity tests in the temperature range of $200-600^{\circ} \mathrm{C}$ are illustrated in Figure 2. It clearly shows that Cu-ZSM5 catalyst is the most active regardless of 


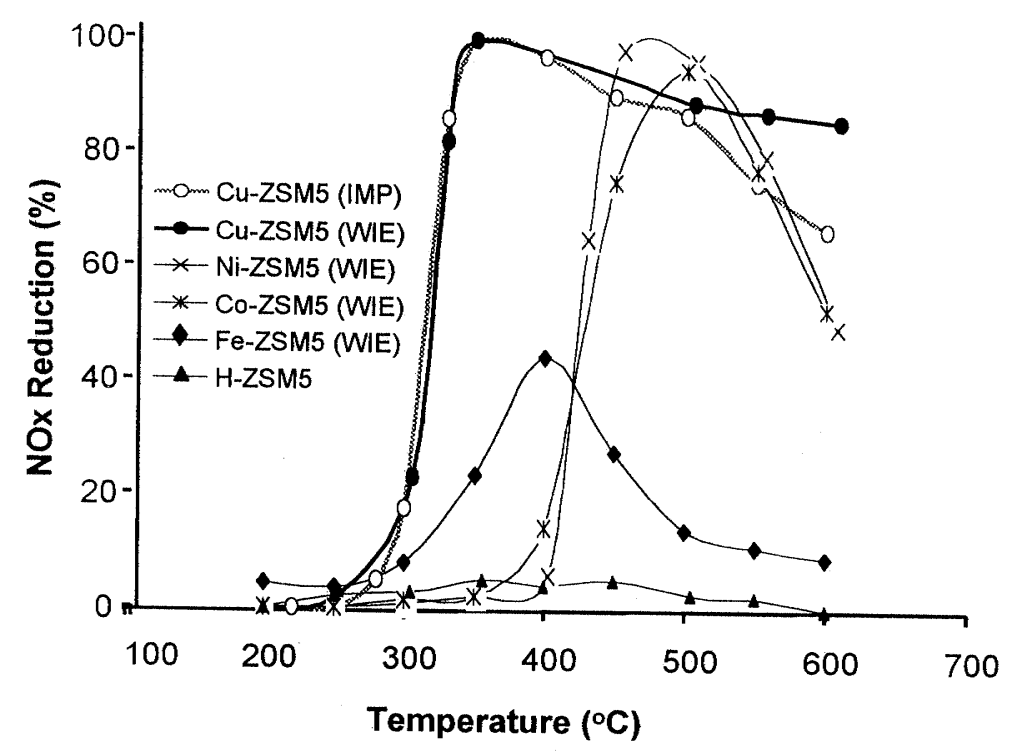

Figure $2:$ Temperature profiles of various metals loaded on H-ZSM-5 zeolite. Feed gases: $\mathrm{NO} 1000 \mathrm{ppm}, \mathrm{i}-\mathrm{C}_{4} \mathrm{H}_{10} 1500 \mathrm{ppm}, \mathrm{O}_{2}$ vol \%, balance He; Flowrate $100 \mathrm{ml}$. $\mathrm{min}^{-1}$. Catalyst $0.18 \mathrm{~g}$.

its preparation methods (i.e. WIE or IMP). The reduction of NOx is negligible below $300^{\circ} \mathrm{C}$ but it drastically increases to almost $100 \%$ at $350^{\circ} \mathrm{C}$. The reduction level slowly declines when the temperature further increases. Profiles of Ni-ZSM5 and Co-ZSM5 catalysts are about the same with negligible NOx reduction below $400^{\circ} \mathrm{C}$. There is a sudden rise in their catalytic activity in the temperature range of $450-550^{\circ} \mathrm{C}$ with maximum reduction of $100 \%$. Further rise in the temperature causes immediate drop in the NOx reduction. Fe-ZSM5 catalyst is the least active catalyst with maximum reduction slightly above $40 \%$ at $400^{\circ} \mathrm{C}$.

Decreasing NOx reduction at high temperatures in all of the tested catalysts may be due to excessive oxidation of the hydrocarbon (equation 3 ) instead of selective reduction of NO (equation 4).

$$
\begin{array}{ll}
61 / 2 \mathrm{O}_{2}+\mathrm{C}_{4} \mathrm{H}_{10} & \rightarrow 4 \mathrm{CO}_{2}+5 \mathrm{H}_{2} \mathrm{O} \\
13 \mathrm{NO}+\mathrm{C}_{4} \mathrm{H}_{10} \rightarrow 4 \mathrm{CO}_{2}+61 / 2 \mathrm{~N}_{2}+5 \mathrm{H}_{2} \mathrm{O}
\end{array}
$$

These reactions are illustrated by the concentration profile in Figure 3 where declining concentration of the hydrocarbon is accompanied by the prevailing formation of $\mathrm{CO}_{2}$
at high temperatures. 


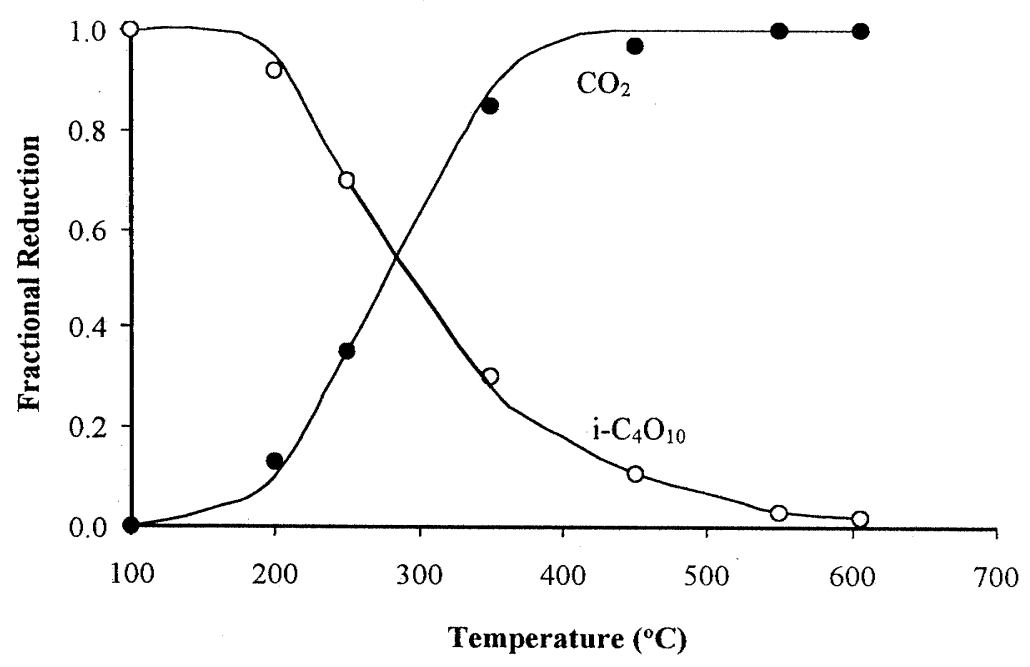

Figure 3 : Concentration profile of $i$-butane and carbon dioxide during HC-SCR of NOx with Cu-ZSM5 catalyst. Feed gases and conditions as described in Fig. 1.

\subsection{Catalytic activity of Fe-ZSM5}

Many recent papers have suggested Fe-ZSM5 catalyst prepared by sublimation as the potential catalyst for practical application in diesel exhaust environment $[7,13,14,15,16]$. The main reason cited for its high activity is its tolerance towards water vapor and $\mathrm{SO}_{2}$, the two components generally present in diesel exhaust. Our earlier results on Fe-ZSM5 prepared by WIE and IMP are compared with the ones prepared by SUB and SSI as shown in Figure 4.

All of the Fe-ZSM5 catalysts with the exception of Fe-ZSM5 (SUB) show relatively low catalytic activity where the maximum reduction of NOx is only $40 \%$ at $400^{\circ} \mathrm{C}$. These catalysts are not active at temperatures lower than $300^{\circ} \mathrm{C}$ or at temperatures higher than $600^{\circ} \mathrm{C}$. As expected, the highest NOx reduction of about $60 \%$ is obtained by the one prepared through sublimation method. This maximum reduction, nevertheless, is lower than reported values of around $80 \%[7,16]$. This could be attributed to the low loading of active iron species (Fe/Al $\sim 0.65$ ) or formation of inactive iron oxides particles during preparation process (i.e. excessive washing and oxidation in air). The presence of iron oxides particles could promote the formation of $\mathrm{CO}$ [7] as shown in Figure 5. In all $\mathrm{Fe}-\mathrm{ZSM} 5$ catalysts, $\mathrm{CO}$ formation becomes evident at temperatures above $350^{\circ} \mathrm{C}$, some of which exceeds $1000 \mathrm{ppm}$. Catalyst prepared by SSI method nevertheless produces relatively low $\mathrm{CO}$ than any other Fe-ZSM5 catalysts. 


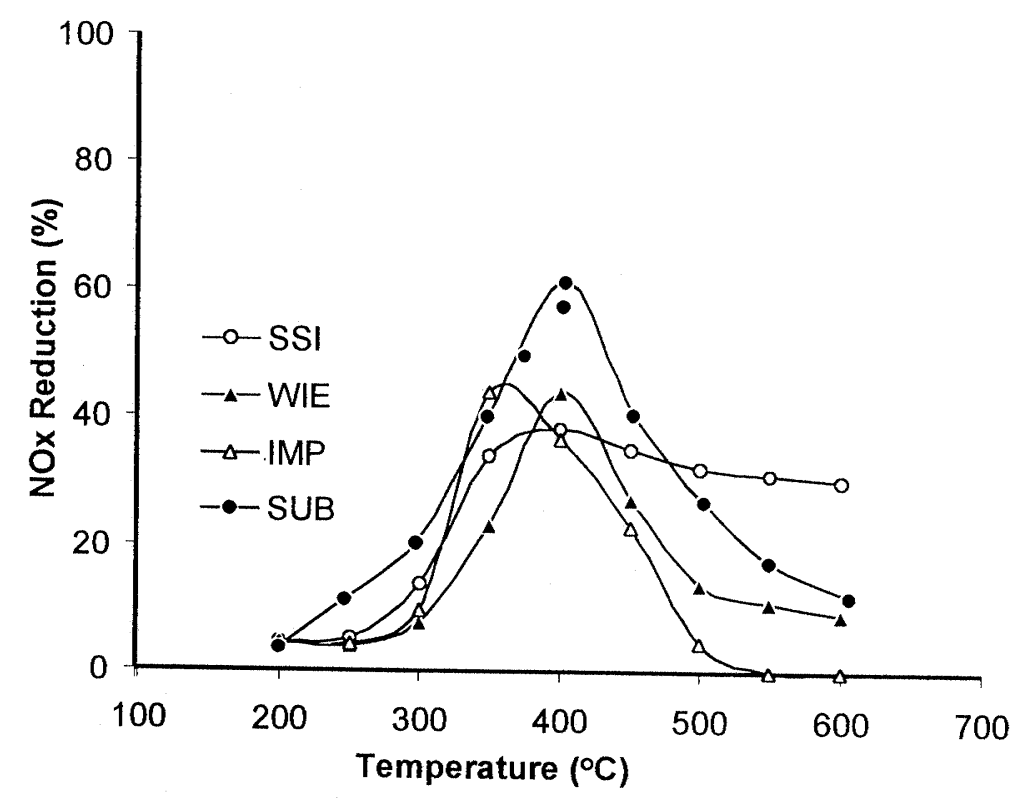

Figure 4: Catalytic activity of Fe-ZSM5 catalysts prepared from various methods. Feed gases and conditions as described in Fig. 1.

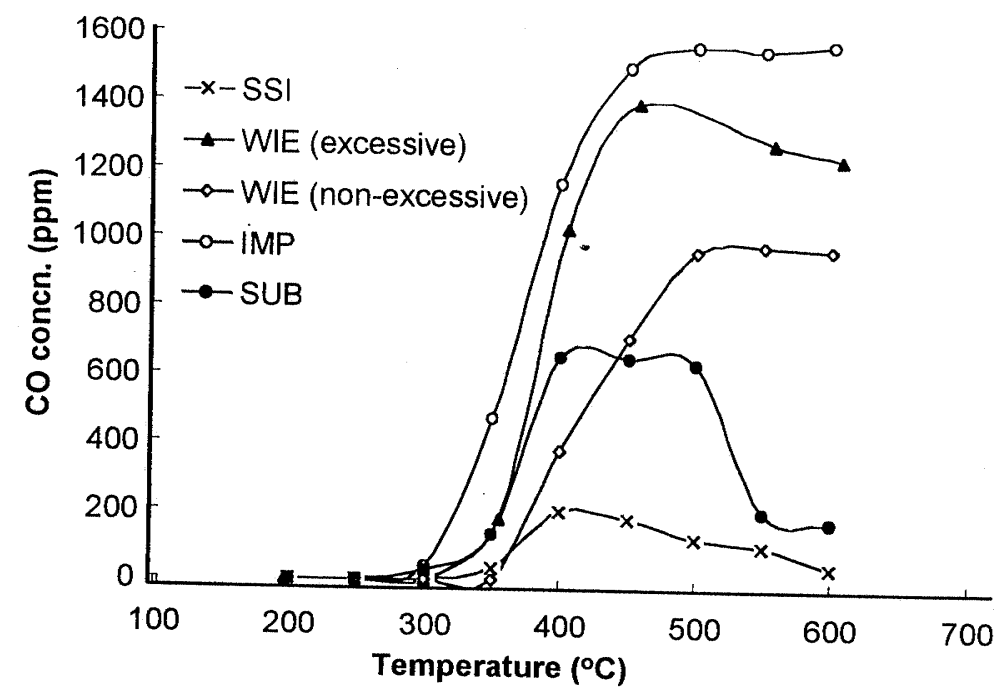

Figure 5 : Formation of CO during HC-SCR of NOx with Fe-ZSM5 catalysts

\subsection{Catalytic activity of Cu-ZSM5}

$\mathrm{Cu}-\mathrm{ZSM} 5$ appears to be the most intensely studied catalyst in the HC-SCR system since the pioneer work of Iwamoto and Hamada [4]. In fact our results on Cu-ZSM5 in 
Figure 2 clearly shows its superior performance than other catalysts. Therefore, further tests were carried out to evaluate its activities in a range of space velocity, hydrocarbon and oxygen concentrations, various $\mathrm{Si} / \mathrm{Al}$ ratios of the ZSM5 zeolite and durability in $\mathrm{SO}_{2}$ and water vapor.

\subsubsection{Effect of space velocity, hydrocarbon and oxygen}

Figures 6 and 7 illustrate the performance of Cu-ZSM5 catalyst in a range of temperature with various composition of oxygen and hydrocarbon. In the absence of oxygen, there is still some NOx reduction taking place over the catalyst as reported in the literature [4]. This is the region where the catalyst might be operating in the so-called "catalytic decomposition" process (i.e. NO decomposes into $\mathrm{N}_{2}$ and $\mathrm{O}_{2}$ ). The presence of hydrocarbon and oxygen changes the process from decomposition to reduction, which significantly improves the NOx reduction. The profile in Figure 6 clearly shows that the presence of only $1 \% \mathrm{O}_{2}$ is enough to improve the reduction level from $10 \%$ to $100 \%$. Further increase of $\mathrm{O}_{2}$ in the feed gas stream, however, impairs the activity of the Cu-ZSM-5 catalyst. This may be due to the tendency of the hydrocarbon to react directly with the excess $\mathrm{O}_{2}$ (i.e. without involving NO).

Results from space velocity test are presented in Figure 8. The test was carried out by changing the weight of catalyst from 0.25 gram to 0.04 gram that corresponded to space

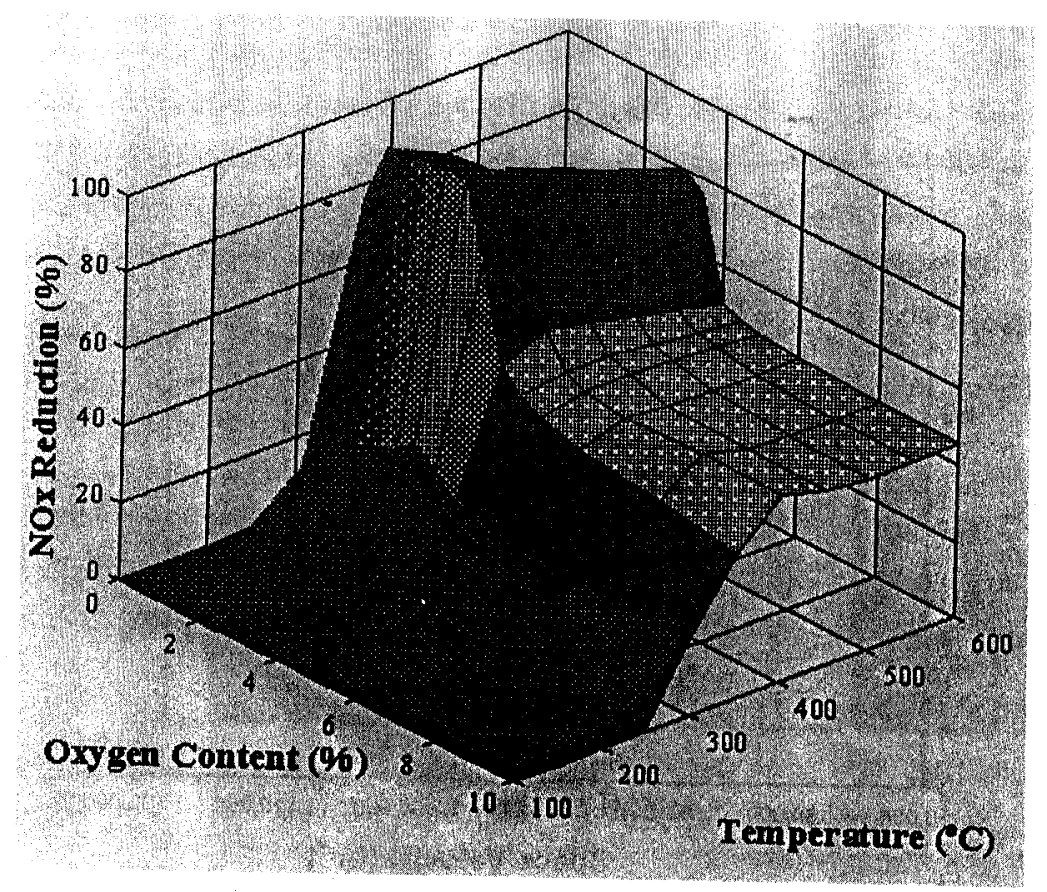

Figure 6 : Catalytic activity of Cu-ZSM5 (45) as a function of oxygen content and temperature. Fixed conditions: $i-C_{4} H_{10} 1500 \mathrm{ppm}, \mathrm{SV} 20,000 \mathrm{hr}^{-1}$ 


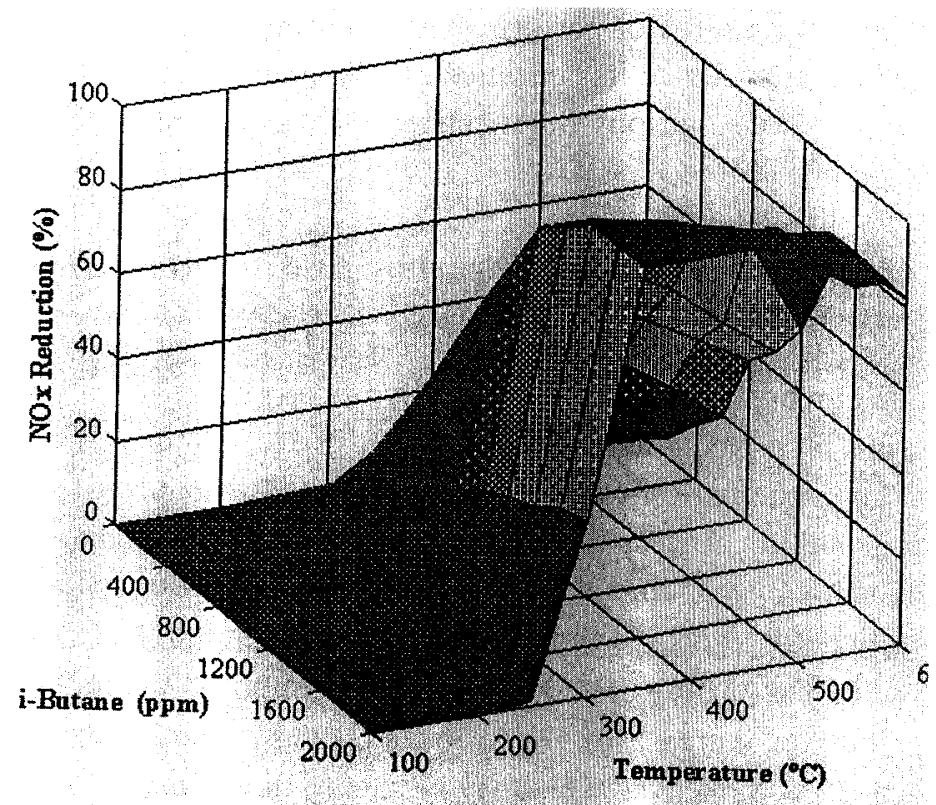

Figure 7: Catalytic activity of Cu-ZSM5 (45) as a function of concentration of hy- . drocarbon $\left(\mathrm{i}-\mathrm{C}_{4} \mathrm{H}_{10}\right)$ and temperature. Fixed conditions: $\mathrm{O}_{2} 3$ vol\%, $\mathrm{SV}$ 20,000 $\mathrm{hr}^{-1}$

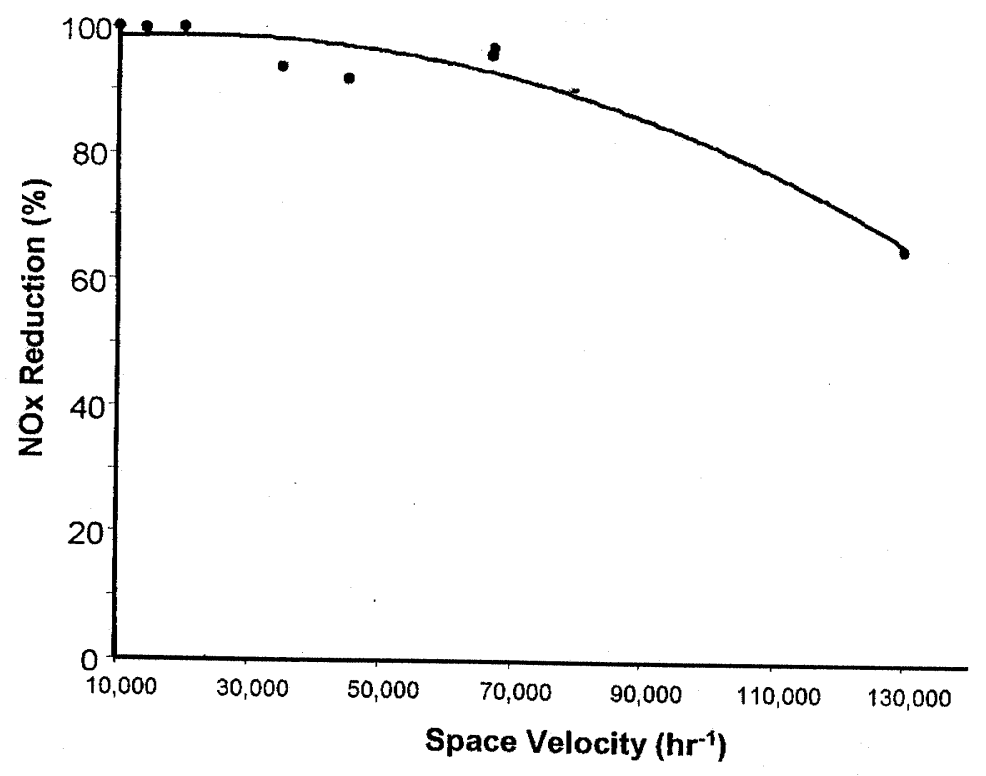

Figure 8: Catalytic activity of Cu-ZSM5 in a range of space velocity. Feed gases and conditions as described in Fig. 1. 
velocity of $10,000 \mathrm{hr}^{-1}$ and $120,000 \mathrm{hr}^{-1}$ respectively. It shows that the catalyst is stable in a large range of space velocity. The reduction level only slightly decreases from about $100 \%$ at $5,000 \mathrm{hr}^{-1}$ to about $75 \%$ at $120,000 \mathrm{hr}^{-1}$.

\subsubsection{Effect of water vapor and $\mathrm{Si} / \mathrm{Al}$ ratio}

The presence of water vapor can deactivate the performance of the Cu-ZSM5 [3]. Water vapor poisons by attacking the acid sites, sometime to dealumination at higher temperature and agglomeration of catalyst particles, which in turn reduces the effective surface area and thereby drop in the catalytic activity. It is reported that in wet stream, active $\mathrm{Cu}^{2+}$ species agglomerate to form inactive $\mathrm{CuO}[6]$.

$$
\mathrm{ZCu}^{2+}(\mathrm{OH})^{-} \rightarrow \mathrm{Z}^{-} \mathrm{H}^{+}+\mathrm{CuO}
$$

(' $\mathrm{Z}$ ' represents zeolite structure with -1 net charge)

It appears that poisoning of active metal species by water vapor is not limited to $\mathrm{Cu}$ ions. Other metals such as $\mathrm{Pd}$ is also reportedly prone to forming inactive metal oxide in wet stream [17]. Based on the Raman Spectrum analysis, the study reported that PdZSM5 catalyst with intense PdO band showed low NO reduction activity whereas the one with no PdO bands showed high NO reduction activity. With regards to dealumination, it is reported that elevated temperature causes migration of a part of $\mathrm{Al}$ from its lattice positions into cation position from which it can be easily removed [18]. However, silicon migration forcing the unit cell shrinkage might help to stabilize and strengthen the zeolite structure in wet stream [18].

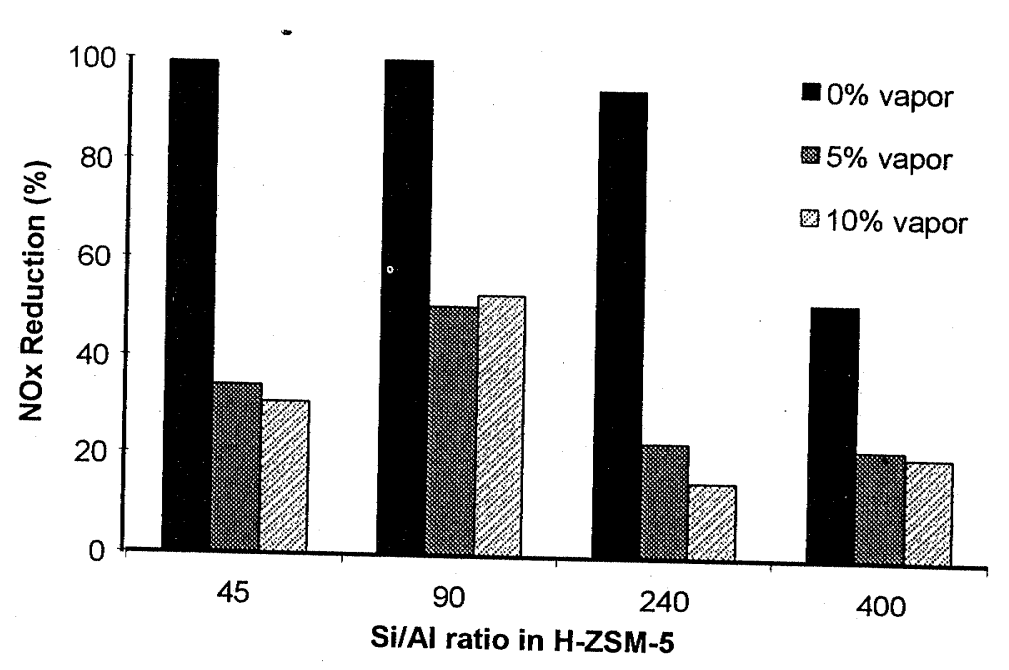

Figure 9: Catalytic activity of Cu-ZSM5 with different Si/Al ratios. Feed gases and conditions as described in Fig. 1. The same catalysts were used in both dry and wet conditions. 
Four samples of Cu-ZSM5 catalysts with respective Si/Al ratio of 45, 90, 240 and 400 were prepared through ion-exchange process to assess their stability in wet stream. Figure 9 shows that the NOx reduction is almost $100 \%$ in the absence of water vapor for all catalysts except Cu-ZSM5 (400). The significantly low maximum reduction in dry feed for Cu-ZSM5 (400) could be due to limited Al lattice available for sitting of active copper species. Introduction of $5 \%$ and $10 \%$ water vapor causes immediate drop in the NOx reduction level for all of the catalysts. Increasing the $\mathrm{Si} / \mathrm{Al}$ ratio from 45 to 90 , nevertheless, seems to slightly strengthen the performance of the catalyst in wet stream.

Further durability test were carried out on Cu-ZSM5 (45) and Cu-ZSM5 (90) with alternate water feed for 48 hours as illustrated in Figure 10. It shows reversible effect of water vapor on both catalysts. The presence of $10 \%$ water vapor in the feed gas stream immediately reduces the catalytic activity in which the reduction level drops from almost $100 \%$ in the absence of water vapor to $50 \%$ in the presence of water vapor. It is of interest to note that the NOx reduction level for Cu-ZSM5 (45) catalyst is always lower than that of Cu-ZSM5 (90) in wet stream. This suggests that H-ZSM-5 zeolite with high silica content may reduces the availability of acid sites for attack by water vapor. However, extremely high silica content may also limit the amount of . active copper species exchanged into the zeolite matrix.

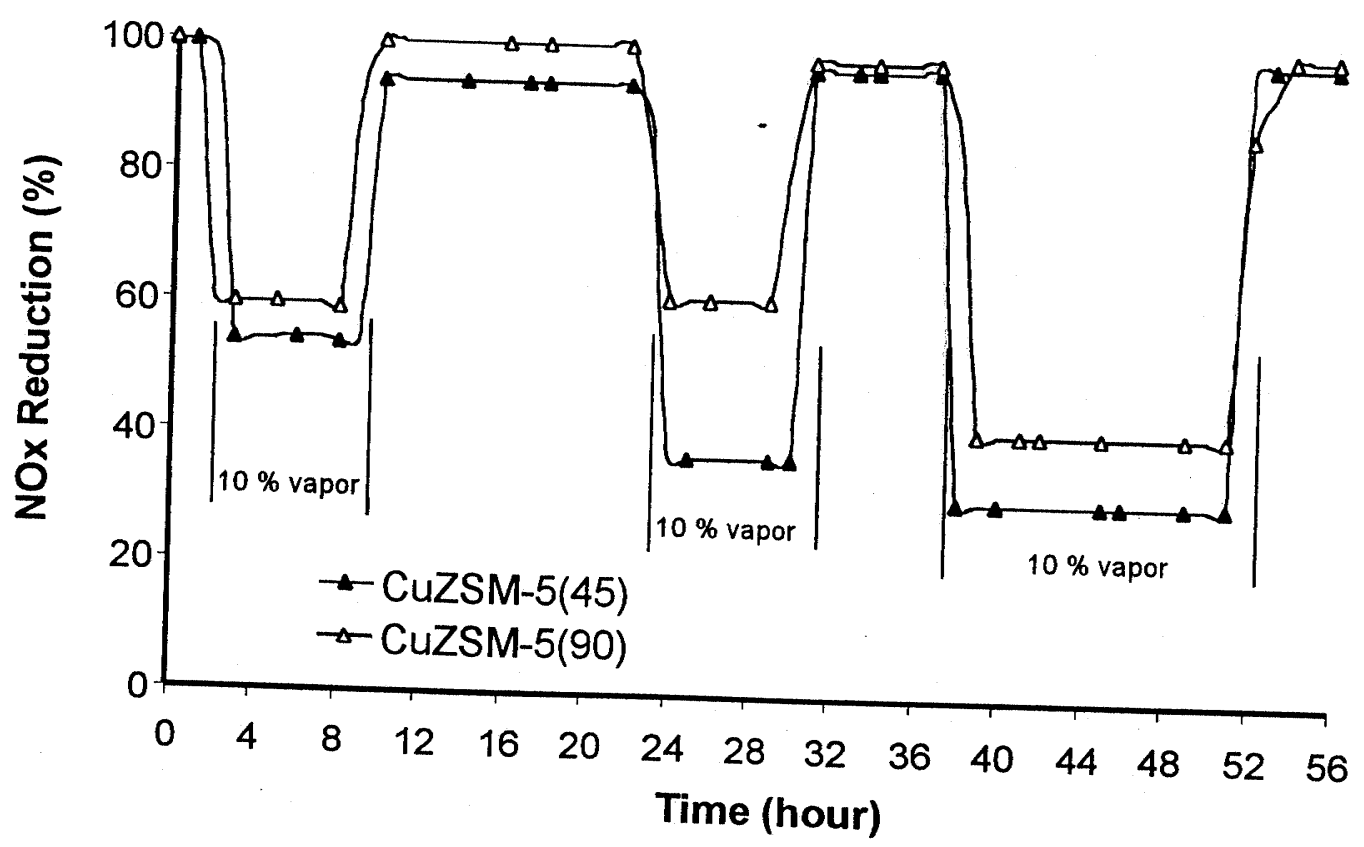

Figure 10 : Durability test on Cu-ZSM5 catalysts. Fixed conditions: $350^{\circ} \mathrm{C}$ 


\subsubsection{Effect of sulfur dioxide}

In addition to water vapor, $\mathrm{SO}_{2}$ that originates from diesel fuel and subsequent oxidation during engine combustion, is another poisonous component in diesel emissions $[19,20]$. Figure 11 shows that addition of 50,100 and $200 \mathrm{ppm}$ of $\mathrm{SO}_{2}$ into the exhaust stream causes significant drop in the NOx reduction level from $100 \%$ to below $10 \%$. Although $\mathrm{SO}_{2}$ has been stopped from entering the exhaust mixture, it seems to leave irreversible damage to the catalytic activity. In this regard, it is reported that $\mathrm{SO}_{2}$ acts in two ways to poison the catalyst [7]. Firstly, $\mathrm{SO}_{2}$ prevents total oxidation of the hydrocarbon by reducing its reactivity. Secondly, $\mathrm{SO}_{2}$ forms surface intermediates such as $\mathrm{S}$ and $\mathrm{H}_{2} \mathrm{~S}$ that adsorb on the active sites of the catalyst.

\section{DISCUSSION}

\subsection{Role of support, preparation methods and active sites}

The structure of H-ZSM-5 zeolite plays an important role for the catalytic reduction of NOx through HC-SCR process. The zeolite has distinctively special features such as high surface area with uniformly interconnected channel system, high stability from tetrahedral framework and high acidity. Above all, its medium pore size between those of Y zeolite (i.e. large pore size) and mordenite (i.e. small pore size) allows it to possess unusually high selectivity for NOx reduction [3]. This is important since extremely small pore size such as ferrerite with 10-ring system has shown to impose diffusional constraint for reaction involving large hydrocarbon molecules [21].

While the catalyst support provides sites for active metal species, catalyst preparation method influences the distribution and nature of active species. It is very likely that catalyst prepared by impregnation will have its active metal species located near the pore mouth whereas the one prepared by ion exchange or sublimation possesses active

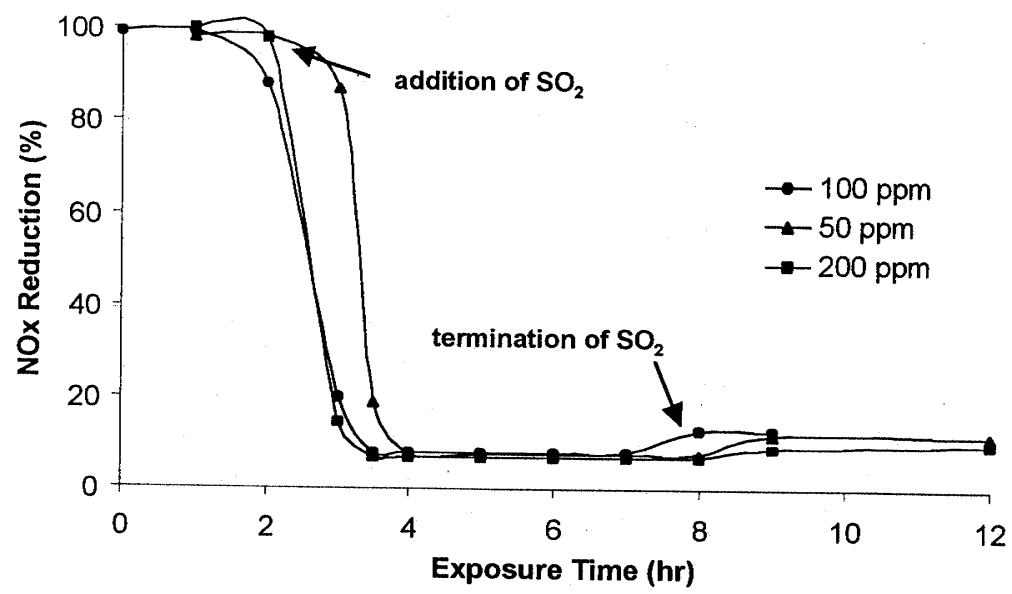

Figure 11 : Effect of sulfur dioxide on catalytic activity of Cu-ZSM5 catalyst. 
metal species deep in the zeolite channel. During ion exchange, copper ions readily penetrate deep and well disperse into the ZSM5 channel. They form stable $\mathrm{Cu}-\mathrm{O}$ interactions that do not alter the charge of the zeolite framework [22].

$$
\mathrm{Cu}^{2+}\left(\mathrm{NO}_{3}{ }^{-}\right)_{2}+2 \mathrm{H}^{+} \mathrm{Z}^{-} \rightarrow 2 \mathrm{HNO}_{3}+\mathrm{Cu}^{2+}\left(\mathrm{Z}_{2}\right)_{2}
$$

It is described that $\mathrm{Cu}^{2+}$ sits on the zeolite $\mathrm{Al}$ site in two forms [23]; $\mathrm{Z}^{-}-\mathrm{Cu}^{2+}-\mathrm{OH}^{-}\left(\mathrm{OH}^{-}\right.$ acts to compensate extra +ve charge of the metal cation) and $\mathrm{Z}^{-}-\mathrm{Cu}^{2+}-\mathrm{Z}^{-}$(one divalent cation on Al pair site). An XRF study in reference [24] showed that the first form, dominant in high $\mathrm{Si} / \mathrm{Al}$ zeolite, was not stable for the reduction of NO. However, the second form, dominant in low $\mathrm{Si} / \mathrm{Al}$, was stable for the reduction of NO. The study highlighted that the first form has high tendency to form inactive $\mathrm{CuO}$ and associated agglomeration [24].

For iron species that is highly sensitive to oxidation, impregnation method is not suitable. Iron species deposited on the pore mouth can be easily oxidized to form inactive iron oxides particles before they could enter the zeolite channel. Iron oxides particles on the other hand, aggressively promote the formation $\mathrm{CO}$ as shown in our result and in other reported studies $[7,13,16]$. This could also explain why our Fe-ZSM5 catalysts did not show high activity for the reduction of NOx. However, well dispersed active iron species in the zeolite structure can be achieved through sublimation method in which $\mathrm{Fe}$ ions are carried in vapor form (i.e. $\mathrm{FeCl}_{3}$ ) into the channel system before deposition. An ESR study postulated that during sublimation, iron species $\left(\mathrm{FeCl}_{2}\right)^{+}$replaces completely Bronsted acid sites to form ionic species and only a small part becomes inactive iron oxide particles [16]. It is reported that $\mathrm{FeCl}_{3}$ reacts with Brönsted acid site of the H-ZSM5 to produce binuclear iron complex in which the oxidation state of Fe moves reversibly between +2 and +4 [13]. It is also reported that cavities in the ZSM-5 contain a variety of Fe-oxo-complexes and no naked $\mathrm{Fe}^{3+}[15]$.

Like $\mathrm{Cu}$ and Fe species, there are diverse forms of $\mathrm{Co}$ and Ni species in the ZSM5 zeolite support, some of which are inactive for the reduction of NOx. It is reported that $\mathrm{Co}$ exists in three kinds of species [25]: $\mathrm{Co}^{2+}$ or $(\mathrm{Co}-\mathrm{OH})^{+}, \mathrm{Co}_{3} \mathrm{O}_{4}$, and Co oxo-ions [25]. $\mathrm{Co}^{2+}$ species, located in the exchange position of the zeolite, do not catalyze $\mathrm{NO}_{2}$ formation since they are prone to chemisorption by $\mathrm{NO}_{2}$. They become active only at high temperatures to catalyze $\mathrm{NO}$ to $\mathrm{N}_{2} \cdot \mathrm{Co}_{3} \mathrm{O}_{4}$ and multinuclear cobalt ions, Cooxo ions, promote fast formation of $\mathrm{NO}_{\mathrm{y}}$ complexes, an intermediate step for total reduction of NO. An XPS study by Gervasini [22] suggested that Co and Ni ions had less ability than $\mathrm{Cu}$ ions to penetrate into the zeolite structure. Further characterization with nitrogen adsorption isotherm indicated that introduction of $\mathrm{Co}$ and $\mathrm{Ni}$ into the zeolite had caused a significant increase in the external surface area (i.e. higher than the external surface area of $\mathrm{Cu}$-ZSM5) and a marked decrease in the micropore volume (i.e. lower than the micropore volume of Cu-ZSM5) [22]. The study postulated that lower partial charge of $\mathrm{CoO}$ and $\mathrm{NiO}$ oxides might also alter the charge of the host crystalline framework. These factors may explain why Co-ZSM5 and Ni-ZSM5 are catalytically less active than Cu-ZSM5. 


\subsection{Reaction mechanism}

Reaction mechanism in the HC-SCR process is complex due to the formation of intermediate products at various steps in the chemical reactions [2,3,14]. Even though the type of catalyst plays a major influence on the reaction, other factors such as the type hydrocarbon and the presence of other exhaust components may cause a completely different scheme of reaction mechanism. Secondary reactions that produce undesired by-products particularly $\mathrm{N}_{2} \mathrm{O}$ and $\mathrm{CO}$ will further complicate the chemical reaction. Nevertheless, it is suggested that the HC-SCR process involves competition of two prime reactions [26].

$$
\begin{aligned}
& a \mathrm{HC}+b \mathrm{O}_{2} \rightarrow c \mathrm{CO}_{2}+d \mathrm{H}_{2} \mathrm{O} \\
& a \mathrm{HC}+b \mathrm{NOx} \rightarrow c \mathrm{~N}_{2}+d \mathrm{CO}_{2}+e \mathrm{H}_{2} \mathrm{O}
\end{aligned}
$$

( $a, b, c, d, e$ represent appropriate constants to balance the equation)

For HC-SCR of NOx with Cu-ZSM5 catalyst, Fritz and Pitchon [2] summarized one of the reported mechanisms as follows.

$$
\begin{array}{ll}
2 \mathrm{NO}-\mathrm{Cu}^{+} & \rightarrow \mathrm{N}_{2}+2 \mathrm{O}-\mathrm{Cu}^{2+} \\
9 \mathrm{O}-\mathrm{Cu}+\mathrm{C}_{3} \mathrm{H}_{6} & \rightarrow 9 \mathrm{Cu}^{+}+3 \mathrm{CO}_{2}+3 \mathrm{H}_{2} \mathrm{O}
\end{array}
$$

$\mathrm{NO}$ adsorbs onto $\mathrm{Cu}^{+}$sites before decomposing into $\mathrm{N}_{2}$ and $\mathrm{Cu}^{2+}$ coordinated oxygen. The presence of hydrocarbon such as $\mathrm{C}_{3} \mathrm{H}_{6}$, will regenerate the $\mathrm{Cu}^{+}$active sites by reacting with surface oxygen. For HC-SCR of NOx with Fe-ZSM5 catalyst, the scheme of reactions is proposed as follows [11].

1. Formation of surface nitrates

2. Surface nitrates + hydrocarbon (i.e. $\mathrm{C}_{3} \mathrm{H}_{8}$ ) $\rightarrow$ surface $\mathrm{C}-\mathrm{H}-\mathrm{N}-\mathrm{O}$ deposits

3. C-H-N-O deposits decompose into $\mathrm{NCO}^{-}$species

4. $\mathrm{NCO}^{-}+\left(\mathrm{NO}+\mathrm{O}_{2}\right) \rightarrow \mathrm{N}_{2}+\mathrm{CO}_{2}$

In the reaction scheme, nitro species such as $\mathrm{NO}_{\mathrm{y}}$, complexes with hydrocarbon and transforms into $-\mathrm{NH}_{2}$ or $-\mathrm{CNO}$ groups that are reactive towards impinging $\mathrm{NO}$ or $\mathrm{NO}_{2}$ molecules [14]. On Fe-ZSM5 catalyst, water transforms primary $\mathrm{NO}_{\mathrm{y}}$ groups and helps volatilize carbonaceous deposits [14]. Hadjivanov et al. [11] highlighted 3 criteria for surface species in an active FeZSM-5 catalyst: thermally stable, water resistant and oxygen resistant. The study suggested that $\mathrm{NO}$ and $\mathrm{O}_{2}$ co-adsorp on FeZSM-5 to form $\mathrm{N}_{2} \mathrm{O}_{3}, \mathrm{~N}_{2} \mathrm{O}_{4}$ and nitrates which are all weakly affected by water. This is a result of stronger bond formation in $\mathrm{NO}^{3-}=\mathrm{Fe}^{\mathrm{n}+}$ than that in coordinated water $=\mathrm{Fe}^{\mathrm{n}+}$. On the other hand, water vapor suppresses the formation of surface nitrates on Cu-ZSM5 catalyst. 


\section{CONCLUSION}

Catalytic activity tests have shown the superiority of Cu-ZSM5 catalyst over other transition metals (iron, cobalt, and nickel) loaded on ZSM5 zeolite for the reduction of NOx. It could achieve complete removal of NOx in dry feed but the presence of $10 \%$ water vapor remarkably reduces it catalytic activity. Water vapor causes only reversible effect to the catalyst but the presence of $\mathrm{SO}_{2}$ as little as $50 \mathrm{ppm}$ seems to cause permanent damage to the catalytic activity. Increasing the $\mathrm{Si} / \mathrm{Al}$ from 45 to 90 could somehow increase the stability of the Cu-ZSM5 catalyst in wet stream. However, extremely high $\mathrm{Si} / \mathrm{Al}$ (i.e. 240 or 400 ) shows low catalytic activity, which might be due to limited exchange of active copper species in the zeolite structure. Catalytic activity tests on Fe-ZSM5 show that the one prepared by sublimation (SUB) is the most active with the maximum NOx conversion of about $60 \%$. A large production of $\mathrm{CO}$, which might be catalyzed by iron oxide particles, seem to be the most disadvantage of Fe-ZSM5 catalysts. Regardless of the type of the loaded transition metals, ZSM5 supported catalysts possess narrow operating window that only occurs at relatively high temperatures (i.e. above $300^{\circ} \mathrm{C}$ ) for the removal of NOx.

\section{ACKNOWLEDGEMENTS}

The authors would like to thank the Ministry of Science and Technology, Malaysia and Universiti Sains Malaysia for funding this project (FPP 99/051) under the IRPA shortterm grant.

\section{REFERENCES}

1. P. Zelenka, W. Cartellieri and P. Herzog, App. Catal. B, 10 (1996) 3.

2. A. Fritz and V. Pitchon, App. Catal. B, 13 (1997) 1.

3. M. Shelef, Chemical Review, 95 (1995) 209.

4. M. Iwamoto and H. Hamada, Catal. Today, 10 (1991) 57.

5. C.E. Lindhjem and D.A. Guerrieri, Env. Prog., (1998) 1.

6. M.H. Kim, I.S. Nam, and Y.G. Kim, App. Catal. B, 6 (1995) 297.

7. H.Y. Chen and W.M.H. Sachtler, Catal. Today, 42 (1998) 73.

8. P. Gilot, M. Guyon, and B.R. Stanmore, Fuel, 76 No. 6 (1997) 507.

9. W. Grünert, N.W. Hayes, R.W. Joyner, E.S. Shapiro, M.R.H. Siddiqui, and G.N. Baeva, J.Phys.Chem, 98 (1994) 10832.

10. Y. Yokomichi, T. Yamabe, T. Kakumoto, O. Okada, H. Ishikawa, Y. Nakamura, H. Kimura, and I. Yasuda, App. Catal. B, 28 (2000) 1.

11. K. Hadjiivanov, H. Knözinger, B. Tsyntsarski, and L. Dimitrov, Catal. Lett., 62 (1999) 35.

12. I.O.Y. Liu, N.W. Cant, M. Kogel, and T. Turek, Catal. Lett., 63 (1999) 241.

13. A.A. Battiston, J.H. Bitter and D.C. Koningsberger, Catal. Lett., 66 (2000) 75.

14. H.Y. Chen, T. Voskoboinikov and W.M.H. Sachtler, J. Catal., 186 (1999) 91. 
15. T.V. Voskoboinikov, H.Y. Chen, and W.M.H. Sachtler, App. Catal. B, 19 no 3-4 (1998) 279.

16. H.T. Lee and H.K. Rhee, Cat. Lett, 61 (1999) 71.

17. H. Ohtsuka, and T. Tabata, App. Catal. B, 21 (1999) 139.

18. S. Bhatia, Zeolite Catalysis: Principles and Applications, CRC Press, Boca Raton, 1990, p. 7.

19. J.C. Summers, J.F. Skowron, W.B. Williamson, and K.I Mitchell, SAE paper No. 920558.

20. W. Chen, H. Lu, C.M. Pradier, J. Paul, A. Flodstrom, J. Catal., 172 (1997) 3.

21. F. Witzel, G.A. Sill, and W. K. Hall, J. Catal., 149 (1994) 229.

22. A. Gervasini, App. Catal. A, 180 (1999) 71.

23. B. Wichterlova, J. Dedecek, Z. Sobalik, A. Vondlovaa, K. Klier, J. Catal. 169 (1997) 194

24. H. Ohtsuka, and T. Tabata, App. Catal. B, 26 (2000) 275.

25. X. Wang, H.Y. Chen, and W.M.H. Sachtler, App. Catal., 29 (2001) 47.

26. J.O. Petuchi and W.K. Hall, App. Catal., 2 (1993) L.17. 